\title{
Chapter 7 \\ Observations of Inland Water \\ Biodiversity: Progress, Needs and Priorities
}

\author{
Eren Turak, David Dudgeon, Ian J. Harrison, Jörg Freyhof, \\ Aaike De Wever, Carmen Revenga, Jaime Garcia-Moreno, \\ Robin Abell, Joseph M. Culp, Jennifer Lento, Brice Mora, \\ Lammert Hilarides and Stephan Flink
}

\begin{abstract}
This chapter aims to assist biodiversity observation networks across the world in coordinating comprehensive freshwater biodiversity observations at national, regional or continental scales. We highlight special considerations for freshwater biodiversity and methods and tools available for monitoring. We also discuss options for storing, accessing, evaluating and reporting freshwater
\end{abstract}

\section{E. Turak}

Office of Environment and Heritage, Level 18, 59-61 Goulburn Street,

Sydney South, PO Box A290, Sydney, NSW 1232, Australia

E. Turak $(\bowtie)$

Australian Museum, 6 College Street, Sydney, NSW 2000, Australia

e-mail: eren.turak@environment.nsw.gov.au

D. Dudgeon

School of Biological Sciences, The University of Hong Kong,

Pokfulam, Hong Kong, SAR, China

e-mail: ddudgeon@hku.hk

I.J. Harrison

Center for Environment and Peace Conservation International,

2011 Crystal Drive, Suite 500, Arlington, VA 22202, USA

e-mail: iharrison@conservation.org

J. Freyhof

German Centre for Integrative Biodiversity Research (IDiv) Halle-Jena-Leipzig,

Deutscher Platz 5a, Leipzig 04103, Germany

e-mail: freyhof@igb-berlin.de
A. De Wever
OD Natural Environment, Royal Belgian Institute of Natural Sciences,
Vautierstraat 29, 1000 Brussels, Belgium
e-mail: aaike.dewever@naturalsciences.be 
biodiversity data and for ensuring their use in making decisions about the conservation and sustainable management of freshwater biodiversity and provision of ecosystem services.

Keywords Freshwater - Biodiversity - Monitoring - Essential biodiversity variables · Methods • Observations

\subsection{Freshwater Biodiversity Observation}

This chapter aims to assist biodiversity observation networks across the world in coordinating comprehensive freshwater biodiversity observations at national, regional or continental scales. We highlight special considerations for freshwater biodiversity and methods and tools available for monitoring. We also discuss options for storing, accessing, evaluating and reporting freshwater biodiversity data and for ensuring their use in making decisions about the conservation and sustainable management of freshwater biodiversity and provision of ecosystem services.

C. Revenga $\cdot$ R. Abell

The Nature Conservancy, 4245 N. Fairfax Drive, Suite 100, Arlington, VA 22203-1606, USA

e-mail: crevenga@tnc.org

R. Abell

e-mail: robin.abell@tnc.org

J. Garcia-Moreno

ESiLi, Het Haam 16, 6846, KW Arnhem, The Netherlands

e-mail: jgarciamoreno@esili.net

J.M. Culp · J. Lento

Canadian Rivers Institute and Department of Biology, University of New Brunswick,

Fredericton, New Brunswick E3B 6E1, Canada

e-mail: jlento@gmail.com

B. Mora

GOFC-GOLD LC, PO Box 47, 6700, AA Wageningen, The Netherlands

e-mail: brice.mora@wur.nl

L. Hilarides · S. Flink

Wetlands International, PO Box 471, 6700, AL Wageningen, The Netherlands

e-mail: Lammert.Hilarides@wetlands.org

S. Flink

e-mail: Stephan.Flink@wetlands.org 


\subsubsection{What Is Freshwater Biodiversity?}

Freshwater biodiversity is the diversity of life in inland (non-marine) waters. It includes both species that accomplish all, or parts of their lifecycles in or on water (i.e., 'real' aquatic species) and 'water-dependent' or 'paraquatic' species such as amphibians and water birds, which depend on inland water habitats during at least parts of their lives. The domain of freshwater biodiversity is defined by the extent of inland water ecosystems, which may be categorised as follows: (1) flowing waters (rivers and streams); (2) lacustrine wetlands (lakes, ponds, etc.); (3) palustrine wetlands (swamps, marshes, fens, bogs); and (4) groundwater systems (e.g., karstic systems, aquifers). Some of these inland waters are not best described as 'fresh', in particular, many lakes and aquifers contain high levels of dissolved salts. Nevertheless, it is more appropriate to consider the biodiversity of these systems as freshwater rather than as part of the terrestrial (Chap. 2) or marine realms (Chap. 6).

\subsubsection{The Need for Special Attention to Freshwater Biodiversity Observations}

Several lines of evidence suggest that rates of decline in freshwater biodiversity have been greater during the last few decades than that of their marine and terrestrial counterparts (Collen et al. 2014; Garcia-Moreno et al. 2014). Monitored populations of freshwater vertebrate species have declined by an average of $76 \%$ over the past 40 years, compared to an average of $52 \%$ decline of all vertebrate populations (McLeland et al. 2014). A panoply of direct and indirect threats affect freshwater species and their habitats (Strayer and Dudgeon 2010). For example, one estimate based largely on global models reports that approximately $65 \%$ of global river discharge - and by extension the aquatic biodiversity supported by these rivers — is under considerable pressure from human activities (Vörösmarty et al. 2010).

The intensity of threats to freshwater species is likely to increase as a result of climate change. Higher temperatures and changed precipitation patterns combined with greater frequency of floods and droughts could result in the loss of freshwater species from their last refuges including from locations currently relatively free from anthropogenic threats or stressors. The reduction and degradation of suitable habitats, the difficulties of dispersal through aquatic environments, and the lack of corridors that link freshwater fragments will make it difficult for fully-aquatic species to move into new, more suitable areas following climate change. Conversely, certain invasive species will be able to expand their ranges, putting greater pressure on resident species and accelerate local extinctions (Strayer and Dudgeon 2010). In addition, climate change is creating concerns about water security that could precipitate management decisions that further degrade freshwater ecosystems (Poff et al. 2015). 
Curtailing biodiversity declines and securing freshwater ecosystem services will require local and regional actions specific to these systems at appropriate scales, even when the systems cross national boundaries. Many if not most management and conservation interventions will rightly target freshwater ecosystems rather than species, yet the design of those interventions and the evaluation of their impact on achieving biodiversity goals will require information on multiple dimensions of freshwater biodiversity (i.e., genes, species, populations, communities, and ecosystem structure and function). Monitoring programs, using both traditional and recent, high-technology methods, that take into consideration the special features and structural organisation of inland waters can generate that information.

\subsubsection{Freshwater Biodiversity Observations and Global Targets}

It is widely agreed that goals set by parties to the Convention of Biological Diversity (CBD) to reduce the rate of biodiversity loss by 2010 were not met (Butchart et al. 2010). It would be hard to know if they were, since an evaluation of the state of freshwater biodiversity monitoring networks (Revenga et al. 2005) had earlier identified major shortfalls and gaps in monitoring capacity. One important finding was that existing data on freshwater species and populations were not readily accessible or harmonised in a way that they could be used to inform management decisions (Revenga et al. 2005). Freshwater fishes and water birds were by far the best studied groups, although there were considerable regional differences in completeness of data coverage. By contrast, aquatic plants, freshwater insects, molluscs and crustaceans were poorly known or not assessed in most regions and especially in the tropics (Balian et al. 2008a, b). Nonetheless, even in 2005 there were some well-established regional and continental assessments of freshwater biota (Revenga et al. 2005).

More recently, a 2011 evaluation of the Adequacy of Biodiversity Observation Systems to Support the CBD 2020 Targets (GEO BON 2011) showed that some progress has been made to address the gaps identified by Revenga et al. (2005). A global system of freshwater ecoregions has been completed (Abell et al. 2008), a global database of stream and networks at high spatial resolution has been developed (Lehner et al. 2008), large systematic biomonitoring programs have been established (e.g., CSIR 2007; Hatton-Ellis 2008; Davies et al. 2010; USEPA 2013), and additional regional assessments of freshwater species have been completed (Freyhof and Brooks 2011; Darwall et al. 2011). To address the past under-representation of biodiversity targets in the Millennium Development Goals, their sequel, the Sustainable Development Goals, now more explicitly include targets that are based on the CBD 2020 targets. Importantly, there have also been improvements in access to freshwater biodiversity data which we describe below. 


\subsubsection{Access and Management of Freshwater Biodiversity Data}

Ready access to freshwater biodiversity data and information from all parts of the world is fundamental for the success of freshwater biodiversity observation programs and systems at global, national, regional or local scales. There has been significant progress in this regard during recent years. For example, the EU-funded BioFresh project (http://project.freshwaterbiodiversity.eu), which ran from 2010 until 2014, started building a global platform for freshwater biodiversity data. After the termination of the project, four partner institutes committed to continue the development of this on-line resource through the Freshwater Information Platform (http://www.freshwaterplatform.eu) Major components of this platform include the freshwater metadata journal and meta-database, the freshwater biodiversity data portal, the Global Freshwater Biodiversity Atlas (see Box 7.1) and the freshwater blog. The Freshwater Information Platform is an open body and additional global or continental organisations are welcome to join.

\section{Box 7.1. Global Freshwater Biodiversity Atlas}

The Global Freshwater Biodiversity Atlas (http://atlas.freshwaterbiodiversity.eu) is a global collection of maps to showcase information on freshwater biodiversity and freshwater ecosystems, and includes background data such as freshwater resources, stressors and drivers of biodiversity and ecosystem change. It is a product of collaboration by numerous organisations, initiatives, scientists and projects active in the freshwater biodiversity community. This online information source aims to raise awareness about freshwater biodiversity from multiple perspectives (Fig. 7.1).

As its name suggests, the Atlas includes a collection of published and open-access freshwater biodiversity maps as well as maps developed by different organisations from open-access data. The dynamic maps are accompanied by short articles explaining the maps, including background information and links to publications and data sources related to the specific maps. Contact points of the sources of maps are also provided to ease the access to data and additional information by users.

The atlas provides stakeholders at the science-policy interface, the public and scientists interested in future conservation and sustainable management, with comprehensive information about freshwater biodiversity and its drivers and stressors. It allows those working in freshwater biodiversity to feature their results and make their research outputs visible to the broader community.

Despite such initiatives, much freshwater biodiversity data remain difficult to access. There is a large number of smaller datasets or individual observations of occurrence data that are not integrated into public repositories even though these 


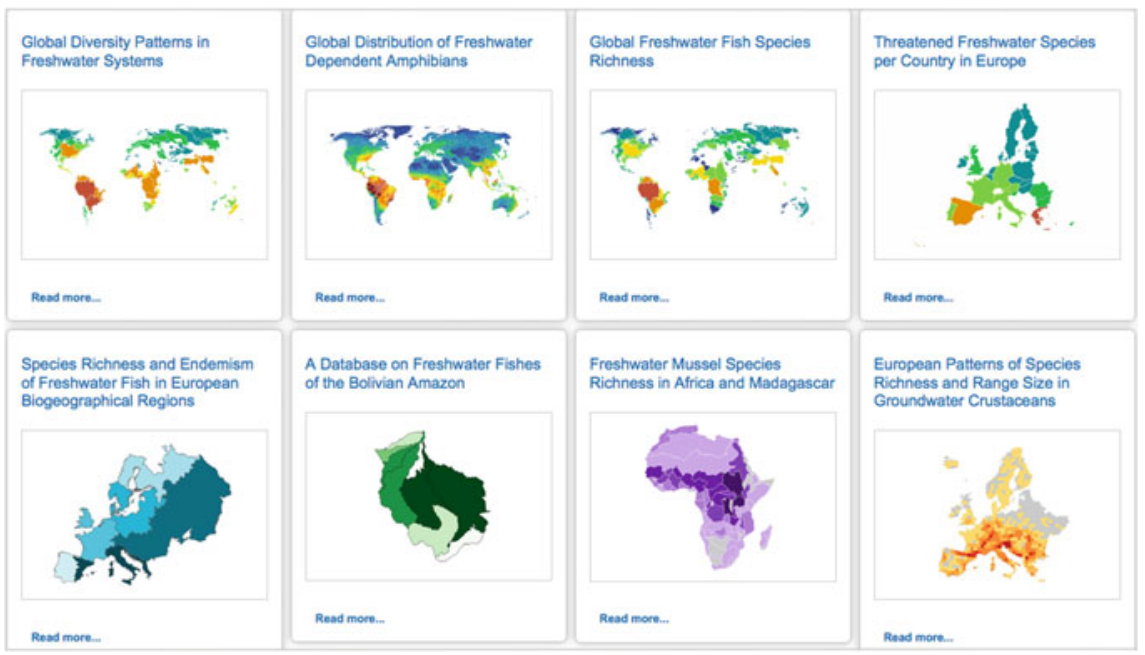

Fig. 7.1 Examples of maps in the Global Freshwater Biodiversity Atlas (Source http://atlas. freshwaterbiodiversity.eu)

data may have been used in scientific papers. Together with editors of leading freshwater journals, BioFresh led a call to make such data available in a standardised format (De Wever et al. 2012), but this has had limited impact so far. Adoption of data publishing practices as part of a mandatory archiving policy may well be required to effect changes in data management practices. In that respect institutes, research groups or individuals could relatively easily set up a data publishing infrastructure by making use of the GBIF Integrated Publishing Toolkit (IPT; http://www.gbif.org/ipt). This could allow the automation of the data publishing process while allowing authors to retain full control of that data. BioFresh or national GBIF nodes (see http://www.gbif.org/participation/list for a list of participants and associated nodes) are able to provide assistance in setting up such a system and often also have a central publishing infrastructure for those who do not have easy access to a server to run the IPT (e.g., http://data.freshwaterbiodiversity. eu/ipt/ for BioFresh). For datasets under construction or that cannot (yet) be released for particular reasons, we recommend documenting their existence in the freshwater metadatabase (see http://data.freshwaterbiodiversity.eu/metadb/bf_mdb_ help.php).

\subsubsection{Improving Our Ability to Track Changes Through Freshwater Biodiversity Observations}

Establishing baseline measures for the conservation status of the Earth's freshwater biodiversity remains an urgent challenge. This baseline is an essential first step for 
tracking changes in relation to the CBD 2020 targets. Considering the challenges of assessing the status of a sufficiently large proportion of freshwater species, Revenga et al. (2005) suggested beginning with a baseline assessment of the extent and conditions of freshwater habitats. Despite the expansion of monitoring programs focussed on river and lake conditions and the improvement in remote sensing technology for tracking wetland extent, a global assessment of the condition and extent of freshwater ecosystems is yet to be completed. A global assessment of threats to human water security and river biodiversity, based mostly on drainage-basin or in-stream indicators, was completed in 2010 (Vörösmarty et al. 2010), providing a coarse picture of the likely extent of imperilment of freshwater habitats.

Biodiversity observation networks can contribute to addressing these challenges by helping to coordinate data collection across large areas. A good example of such harmonisation is the Arctic Freshwater Biodiversity Monitoring Plan (Box 7.2) which details the need for coordinated assessment of Arctic freshwaters, including ponds, lakes and rivers as well as their tributaries and associated wetlands, and provides a framework for improving monitoring efforts in the Arctic region (Culp et al. 2012a, b). The plan represents an agreement among the Arctic nations on the approach to be taken to monitor and assess freshwater biodiversity across the pan-Arctic region. This program is coordinating the efforts of the Arctic countries as they inventory and collect freshwater monitoring data with the goal of producing the first status and trends assessment of Arctic freshwater biodiversity, which is planned for completion in 2017. The initial assessment will evaluate spatial and temporal trends from contemporary and historical time periods, where data allow, which means that by the end of this decade there should be sufficient time-series data to report on changes towards the 2020 CBD targets for the Arctic region. Furthermore, planned periodic re-assessments will continue to inform management decisions beyond 2020. In many other regions of the world there are comparable programs (albeit mostly at much smaller spatial scales) involving the collection of freshwater biodiversity data in a standardised way at least for each individual site and often for a group of sites.

One recent example is the Delaware River Watershed Initiative, a collaborative effort of over 50 organisations working across the Northeast U.S.A.'s $36,570 \mathrm{~km}^{2}$ Delaware River Basin. The initiative has at its core the implementation of standardised monitoring protocols to assess its impact on water quality (see www.ansp. org/drwi). Although freshwater species and population data are not being collected in the service of assessing biodiversity per se, the data are being housed in an open-access database and may prove useful for evaluating species trends in the basin over time.

In general, the data collection protocols of such basin-scale efforts are tailored to the specific goals of individual programs or research efforts, creating challenges for directly combining the primary data for global or regional assessments. It may, however, be possible to use these primary data to quantify essential biodiversity variables representing main components of freshwater biodiversity (e.g., genetic diversity, community composition, ecosystem function; Pereira et al. 2013). 


\section{Box 7.2. The Arctic Freshwater Biodiversity Monitoring Plan: Circumpolar Biodiversity Monitoring Program}

The Arctic Freshwater Biodiversity Monitoring Plan (CBMP-Freshwater Plan) details the rationale and framework for improvements in Arctic freshwater monitoring, including ponds, lakes, rivers, their tributaries and associated wetlands. The framework facilitates circumpolar assessments by providing Arctic countries with a structure and a set of guidelines for initiating and developing monitoring activities that employ common approaches and indicators. The CBMP-Freshwater Plan is part of the Circumpolar Biodiversity Monitoring Program (CBMP) of the Conservation of Arctic Flora and Fauna (CAFF) that is working with partners to harmonise and enhance long-term Arctic biodiversity monitoring efforts. A major goal is to facilitate detection and communication of environmental and biological change in the Arctic, and stimulate societal responses to significant trends and pressures (Fig. 7.2).

The CBMP-Freshwater Plan resulted from the collaboration of the CBMP Freshwater Expert Monitoring Group (represented by Canada, Sweden, Denmark, Finland, Iceland, Norway, Russia, and USA) and additional international freshwater scientists with a broad range of expertise. Contributors assessed the spatial and temporal coverage of available monitoring data and identified important elements, including environmental stressors, indicators, and Focal Ecosystem Components (FECs) to be incorporated into the pan-Arctic Freshwater Plan. FECs are biotic or abiotic elements, such as taxa or key abiotic processes, which are ecologically pivotal, charismatic or sensitive to changes in biodiversity). The mechanistic link between an environmental or anthropogenic stressor and the FECs was identified through 'impact hypotheses', i.e. predictive statements that outline the potential ways in which selected stressors might impact the structure or function of FECs. Preliminary information on the spatial and temporal coverage of available freshwater monitoring data for FECs was summarised to identify high-quality data sets that will form the basis for the first report on status and trends in freshwater biodiversity in the Arctic, which is planned for completion in 2017. This report will evaluate trends in existing data and identify gaps in monitoring efforts and scientific knowledge of Arctic freshwaters. It will also provide recommendations and guidance for more effective monitoring activities that are coordinated and stressor-targeted. By establishing common approaches for monitoring and assessment, the CBMP-Freshwater Plan and the first status and trends report are intended to improve our ability to detect changes to biodiversity and evaluate stressor impacts on a circumpolar scale, thus facilitating more effective management of these systems. 


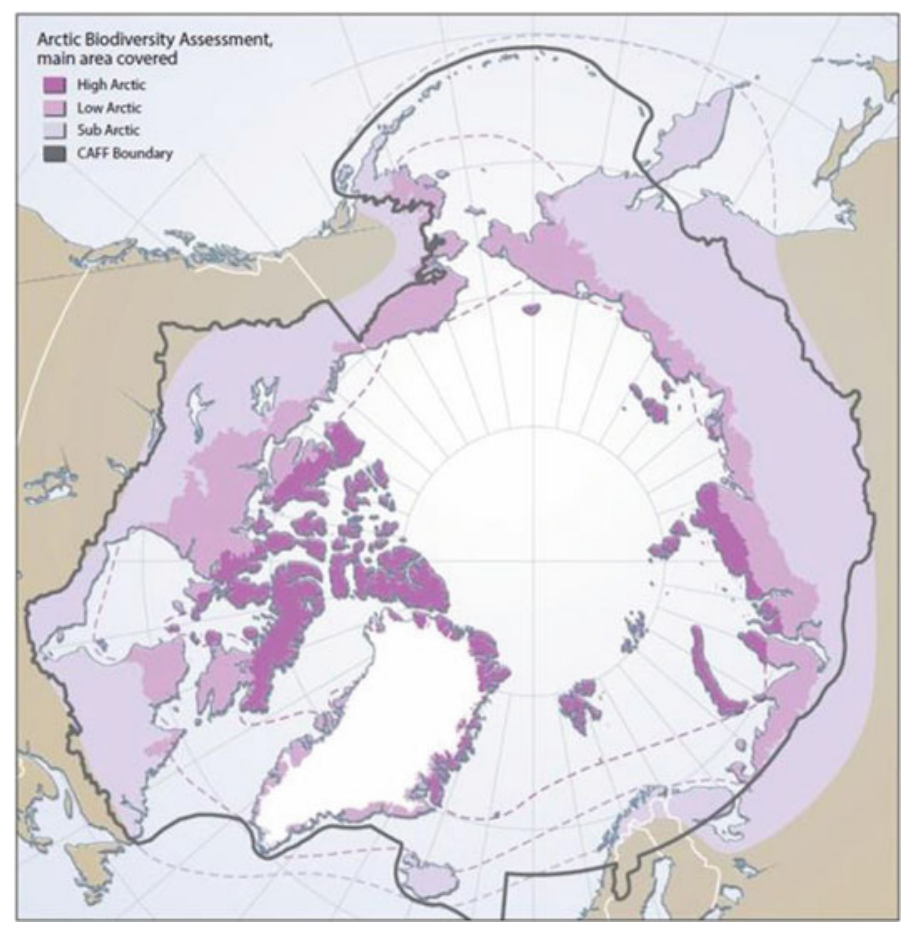

Fig. 7.2 Arctic freshwater boundaries from the Arctic Council's Arctic Biodiversity Assessment developed by CAFF, showing the three sub-regions of the Arctic that are the focus of the CBMP-Freshwater Plan, namely the high (dark purple), low (purple) and sub-Arctic (light purple), and the CAFF boundary (grey line) (Source Culp et al. 2012a)

\subsection{Observations on Components of Freshwater Biodiversity}

Biological monitoring of fresh or inland waters is developing rapidly. There is a diverse array of methods to assess many components of freshwater biodiversity (http://nepis.epa.gov/Exe/ZyPURL.cgi?Dockey=P100AVOF.TXT; see, for example, review by Friberg et al. 2011) and there are practical guides for setting up monitoring programs (e.g., Silk and Ciruna 2005). The priorities for measuring global freshwater biodiversity were identified by Turak et al. (2016) using and Essential Biodiversity Variables (EBV) Framework (Pereira et al. 2013). Here we present some of the important considerations specific to freshwater biodiversity monitoring described by Turak et al. (2016) together with additional information that would be useful for biodiversity observation networks. We have organised this information under the six broad classes of Essential Biodiversity Variables (EBVs; Pereira et al. 2013): i.e., genetic composition, species populations, species traits, community composition ecosystem structure, and ecosystem functioning. We stress, however, that some widely-used indicators for the condition of freshwater ecosystems (e.g., water quality variables) do not fit neatly into these categories. 


\subsubsection{The Spatial Context for Freshwater Biodiversity Observations}

In situ observations of freshwater biodiversity provide information about species or biological communities at discrete locations within a freshwater body (e.g., a river section, a lake margin, or a portion of an aquifer). The use of these observations to infer the status of biodiversity across any large area at a given point in time requires aggregating disparate observations according to relationships between geography and the physical environment on the one hand and geography and freshwater biodiversity on the other. These relationships can also indicate how monitoring efforts can be distributed most efficiently across any given region. Two recent developments provide a foundation for formulating and applying such relationships at regional to global scales.

The first of these (as mentioned in Sect. 7.1.3) is the global biogeographic regionalisation of the world's freshwaters (Freshwater Ecoregions of the World or FEOW; www.feow.org; Abell et al. 2008). FEOW was developed based on freshwater biogeography, defined broadly to include the influences of phylogenetic history, palaeogeography, and ecology. FEOW development used fish species as proxies for the distinctiveness of biotic assemblages, with a few exceptions for extremely data-poor regions and inland seas, where some invertebrates and brackish-water fish were considered, respectively. FEOW offers a framework for development of broad-scale conservation strategies and represents a global-scale knowledge base with the potential for increasing freshwater biogeographic literacy, but it does not provide species occurrence data at a level of resolution that is especially useful for monitoring change over time (Abell et al. 2008).

The second important development is the availability of databases and tools such as HydroBASINS (Lehner and Grill 2013), the most accurate, globally consistent, digital catchment dataset currently available. It provides rapid access to reliable information about drainage basins, globally, at twelve levels of spatial resolution, and includes information on network connectivity. Such landscape units are probably better suited to mapping patterns of biodiversity across broad regions than the uniform, arbitrarily-scaled (typically square) grids used to map patterns of terrestrial or marine biodiversity. These drainage units also have great potential for planning freshwater conservation initiatives and identifying inland water areas for protection (e.g., Heiner et al. 2011).

\subsubsection{Genetic Composition of Freshwater Biodiversity}

Knowledge of the genetic composition and, especially, inter-population variability of freshwater species is of particular importance as river basins and lakes can be relatively isolated 'islands' separated from each other within a terrestrial or marine matrix that most freshwater animals cannot traverse. As a result, gene flow is 
limited and populations of the same species may vary considerably in their genetic composition. This variability has particular applications to the management of freshwater fisheries where loss of genetic variants may have major consequences for ecosystem service provision. Knowledge of inter-population genetic variability can also assist in deciding which populations should be priorities for conservation action, and may be important for assessing risks from invasive species. At present, most genetic data for freshwater species are accessible through GenBank (http:// www.ncbi.nlm.nih.gov/genbank/) where fishes, amphibians, waterbirds and mammals are the best documented groups of freshwater organisms.

Recent advances in high-speed environmental DNA technology (see Taberlet et al. 2012; Goldberg et al. 2015 and references therein) offer great potential for assessing the presence of species and the genetic diversity of biological communities directly from their DNA fragments in the water. DNA extracted from water samples can be used to determine the genetic diversity of the community organisms that were present in that waterbody within up to two weeks before sample collection (see Thomsen et al. 2012). The molecular markers used are usually fragments of the mitochondrial CO1 gene (micro-barcodes), 16s, 18s or 18sV4 rDNA fragments.

Analysis of the mitochondrial CO1 gene is also being used in a global DNA barcoding initiative to catalogue the Earth's biota that already includes many freshwater fishes, amphibians and macroinvertebrates (Hebert et al. 2003; http:// www.barcodeoflife.org). The CO1 gene was selected for barcoding because of its utility in species identification, but it also shows inter-population polymorphism and is used to identify genetic variants in commercial fish species (Ardura et al. 2011). Environmental DNA methods offer possibilities for monitoring metagenomes (i.e., genetic material recovered directly from environmental samples) of entire freshwater ecosystems, capturing both the variability among species and that among populations within species. It also offers new possibilities in freshwater biodiversity monitoring such as obtaining direct measures of the species diversity (though not, at present, species abundances) of individual water bodies including the diversity of microorganisms; enhancing the detection of cryptic, rare or endangered species without having to physically capture individuals; and early detection of invasive species at the expansion front. Nevertheless, this technology is still in its infancy; it would thus be pertinent to caution against over-reliance on it until issues around its sensitivity are resolved (Iversen et al. 2015).

\subsubsection{Observations of Freshwater Species}

The information available on the distribution, population sizes and population structure of freshwater species has greatly improved in recent years, allowing a general enhancement of regional, national, and global biodiversity observation networks. The Freshwater Animal Diversity Assessment (FADA; Balian et al. 2008a, b) provides an overview of genus- and species-level diversity of selected animal taxa groups and macrophytes of the Earth's inland waters. The raw data 
provided by the 163 experts who undertook the initial FADA is accessible through an online database (www.fada.biodiversity.be). Despite many obvious taxonomic and geographic gaps, and hence a need to collect more data (Balian et al. 2008b), FADA provides a much more detailed overview of freshwater biodiversity than had been available previously, and generates essential statistics such as the species richness of major organism groups. In particular, the disproportionate richness of global freshwaters is striking: the total number of freshwater animal species was estimated at 125,531 species, representing $9.5 \%$ of $1,324,000$ animal species described thus far. Insects make up the majority (60.4\%), while only $14.5 \%$ are vertebrates. Furthermore, the 18,235 species of freshwater vertebrates represent $35 \%$ of all vertebrates (about 52,000 species), despite the fact that inland waters occupy less than $1 \%$ of the Earth's surface. Most of these vertebrates are fish (69 \%), followed by amphibians (24\%). The total global number of fish species is presently estimated at 33,715 (Eschmeyer and Fong 2015, based on estimates from Reid et al. 2013). It is apparent that almost $50 \%$ of all fish species inhabit fresh and brackish waters (i.e., 15,062 species, 12,470 of which are strictly freshwater). Freshwater habitats also support $73 \%$ of amphibian species.

The Freshwater Biodiversity Unit of the International Union for the Conservation of Nature (IUCN) has been leading the development of a global assessment of the distribution and conservation status of freshwater organisms (Carrizo et al. 2013). These assessments bring together the most updated taxonomy and the extensive knowledge from thousands of regional experts. Assessments undertaken thus far have focused on fishes, molluscs (mainly unionid bivalves), decapods (crabs, crayfish and shrimps), Odonata (dragonflies and damselflies), and selected plant families (Carrizo et al. 2013). These taxonomic groups encompass a range of biogeographic distributions, habitat preferences and feeding habits, thereby offering a representative view of the ecology and conservation status of freshwater ecosystems. In addition, many of the assessed taxa are good indicators for environmental health in freshwater systems.

Importantly, the IUCN assessments of species are based upon the most comprehensive and accurate information available, involving collation of data on taxonomic status, ecology, distribution, spatial and temporal trends in abundance, as well as the threats they face, their use by humans and conservation measures in place to protect them. The integration of these data results in a classification of extinction risk according to IUCN Red List categories (Extinct, Extinct in the Wild, Critically Endangered, Endangered, Vulnerable, Near threatened, Least Concerned, Data Deficient). The species' ranges are mapped to HydroSHEDS (http://www. hydrosheds.org/; Lehner et al. 2008), but in the near future these data will be transferred to HydroBASINS (http://www.hydrosheds.org/page/hydrobasins), an updated version of HydroSHEDS that includes a coding system that captures the hierarchical spatial relationship among basins. All information on species included in the IUCN database is both widely available and freely accessible through the Red List of Threatened Species (http://www.iucnredlist.org/). Because these data are available at basin or sub-catchment units, they can be combined with information 
on population, land use and other types of data that are used for water resource management.

Modelling techniques that allow mapping of suitable habitats for individual species are increasingly being applied to freshwater species (e.g., Bush et al. 2014b). These models use species occurrence data together with digital data on environmental layers to help predict where species might occur, allowing targeted in situ observations or monitoring of species of particular interest or of conservation concern. If climatic variables are included among the environmental data, these models offer the potential to coarsely predict how species distributions may shift in response to global climate change (e.g., Bush et al. 2014a).

\subsubsection{Observations of Freshwater Species Traits}

Species traits have widely been used to characterise freshwater assemblages or communities, and may include aspects of morphology, function, physiology, behaviour, habitat use, reproduction and life history. Commonly documented traits include: trophic ecology (or functional feeding groups); oxygen or nutrient requirements; thermal range, or tolerance to pollutants, acidity, desiccation, turbidity, etc.; preference for particular substrates, flow regimes of microhabitats; locomotion or dispersal ability; body form; and life span, dormancy, and timing and frequency of breeding etc. Species-trait databases have been developed in some regions for certain taxa, most commonly fishes and macroinvertebrates (http:// www.freshwaterecology.info/; http://eol.org/traitbank; http://www.epa.gov/ncea/ global/traits/; Schmidt-Kloiber and Hering 2015), but plankton, diatoms and macrophytes are also represented. However, such trait-specific data are still lacking for many taxa and in most parts of the world, and fundamental facts about even the basic ecology of many common species are lacking, especially in the tropics.

\subsubsection{Observations of the Composition of Freshwater Communities}

Information on the composition of freshwater assemblages has been employed with some success to assess the condition of freshwater ecosystems, and statements about desirable composition of freshwater biota have been integrated into environmental legislation in countries in Europe and elsewhere (Friberg et al. 2011). The groups most widely used in examining the composition of biological communities in freshwater include macroinvertebrates, benthic algae, macrophytes, phytoplankton and fishes. Community composition metrics typically provide a quantitative measure of departure from reference conditions representing taxonomic completeness of the community (see Hawkins 2006). Reference conditions may be represented by 
relatively undisturbed reference sites or constructed using multiple lines of evidence, and may include the opinion of expert panels (Stoddard et al. 2006).

When the reference condition is represented by extant reference sites, environmental variables thought to be unaffected by human activities may be used to predict the probability of occurrence of a taxon at a site based on the site environmental characteristics. Taxa that have a high probability of occurring at a location are considered to be a natural component of the community at a site if the site's condition was equivalent to a reference site (i.e., unimpaired). Different metrics may then be used to quantify the difference between the predicted and observed community at any putatively impaired or impacted site. The simplest of these metrics is the number of taxa, which is in essence a measure of taxonomic completeness. Another widely-used metric is the ratio of average scores of pollution tolerance of the predicted and observed communities, based upon the combined pollution tolerance scores assigned to each taxon. Note that assignment of such tolerances typically requires good knowledge of the ecology of component species in the community and such information is frequently unavailable.

Widely used metrics of community composition assume that the detection of a species at a location is determined by the suitability of a habitat for colonisation by that species together with its ability to get there. Hence species interactions, for example, predation, competition, parasitism etc., are not incorporated into these assessments.

Despite being integrated into large biomonitoring programs, the data available on the composition of freshwater biological communities are biased and patchy, with no data being available for extensive areas of the Earth at any given point in time. This makes it difficult to determine temporal changes in biodiversity or to compare the status and trends in biodiversity among regions. However, the data that are available can be combined with spatially-continuous remotely-derived environmental layers to model community-level properties of biodiversity such as richness (alpha diversity) and compositional turnover (beta diversity) across large regions (see Ferrier 2011). The applications of these modelling approaches to regional and global biodiversity observations are discussed in Chap. 10.

\subsubsection{Observations of the Structure of Freshwater Ecosystems}

The persistence of freshwater species and communities is greatly influenced by the spatial arrangements of suitable habitats in the landscape and in particular, the presence and location of barriers to the movement of freshwater species, including those introduced by humans (e.g., dams). Observations of ecosystem structure for tracking changes in freshwater ecosystems include measuring changes in the extent of inland water habitats such as wetlands, lakes, rivers and aquifers. Remote sensing technologies for mapping the extent of wetlands and lakes is advancing rapidly (see Chap. 8). Smaller-scale habitat extent observations may encompass the extent of pools, riffles, and runs in streams, or the substratum (e.g., grain size) and flow 
characteristics in riffles; the area and depth of large pools in rivers, or the presence of gravel beds and channel braiding; and the connectivity of floodplains and backwaters with river channels. Such smaller-scale observations are particularly useful in mapping habitat needs of single species. For example, salmonid habitats in rivers can be mapped based on combined measurements of substratum grain size and water depth, and today's remote sensing capability can facilitate these observations (Carbonneau and Piégay 2012). In situ observations of physical and chemical characteristics of water are also an essential component of assessments of ecosystem structure in the context of monitoring freshwater biodiversity.

Advances in remote sensing technologies are increasingly enabling these observations on habitat structure to be made from space and depending on the ecosystem, with fewer in situ observations (see also Chap. 8). The advent of the Sentinel constellations (Sentinel-1 and -2 satellites in particular) as part of the European Copernicus Programme and the NASA Landsat Data Continuity Mission, will ensure continuous provision of Earth Observation data at high spatial resolution $(10-30 \mathrm{~m})$ and at higher time frequency (3-5 days combining Landsat 8 and Sentinel-2 satellites). The recent advent of time-series analysis algorithms combined with higher processing capabilities will enable monitoring of seasonal variations of habitat biophysical characteristics, and support potential development of early warning systems.

\subsubsection{Observations of Freshwater Ecosystem Functioning}

The use of indicators of ecosystem functioning, other than those that may be extrapolated from water-quality data, in monitoring or reporting on the condition of freshwater ecosystems, is rare. The relationship between biodiversity and ecosystem functioning is a growing research area but will need considerable further development before it will be possible to include measures of ecosystem functioning in freshwater biodiversity observations or link changes in biodiversity or ecosystem health to changes in functioning (see Dudgeon 2010). The attributes of ecosystem function that offer the greatest potential for monitoring changes in freshwater ecosystems include rates of organic matter processing (especially leaf litter breakdown in streams), primary production, rates of ecosystem metabolism at different scales (e.g. small patches of river sections), and aspects of secondary production such as fishery yields. Functional measures provide information not provided by measures of community composition. They more directly indicate changes in ecosystem services and can serve as early warning signs of sub-lethal effects that may lead to changes in community composition and abundance of species of conservation concern.

A complicating factor in decisions about whether to use functional attributes in biodiversity observations (and how to interpret them) is that it is not generally possible to predict how functioning changes with species loss. Some species may be 'redundant' so that their loss has little impact on overall functioning (e.g., a loss of a 
single algal species may have negligible effect on overall algal production). Conversely, the loss of certain species (e.g., keystone species such as the beaver, Castor spp.) may have a large effect on functioning even if their loss is reflected (at least initially) in minor changes in community composition. For most freshwater species, and virtually all ecosystems, we are not yet in a position to predict the magnitude of structural redundancy in relation to a given ecosystem function, or to identify the role of individual species maintaining that function. Thus structure may change and function remain unchanged (hence structure is a more sensitive indicator and needs to be closely monitored), or function may change before any structural change has occurred (so function is more sensitive), or there may be no consistent relationship between the two and so, ideally, both need to be monitored (Dudgeon 2010). Further complexity arises from the possibility that function does not respond linearly to changes in environmental conditions: leaf-litter breakdown rates in streams can increase in response to nutrient enrichment until some critical level when they begin to decline; primary productivity is likely also to show a positive or hump-shaped response to nutrient enrichment. Accordingly, our ability to predict the condition of biodiversity at a site from measurements of ecosystem functioning alone may be limited, nor are such measures likely to be helpful when we are concerned with assessing trends in the populations of rare species that may well be so scarce as to have become functionally 'redundant.'

\subsection{Use of Freshwater Biodiversity Data in Decision-Making}

Efficient investment of resources in protecting freshwater species requires combining actions targeted at the level of ecosystems and landscapes and those that target individual species of conservation concern. The efforts invested in freshwater biodiversity observations and the evaluation of monitoring data must take into account the need to achieve a balance between information needed on individual species of concern with information on other components of biodiversity (such as community composition; Box 7.3, Fig. 7.3a).

In prioritising species for monitoring or for repeated or long-term observations, some of the major factors to consider are the level of threat (IUCN Red List status; local classifications of species at risk or the relevant protected-species legislation); regional freshwater conservation targets; community interest in iconic species or those otherwise of particular concern to humans; and species that are essential as sources of food or habitat for threatened species.

Actions that can address the threats to freshwater ecosystems across drainage basins or in broader regions are especially important for conserving biodiversity, but these actions must be prioritised so that resources are spent where greatest benefits can be achieved. Freshwater conservation planning tools can help this prioritisation (Box 7.3 Fig. 7.3b; also see Linke et al. 2011). Such tools require data 
(a)

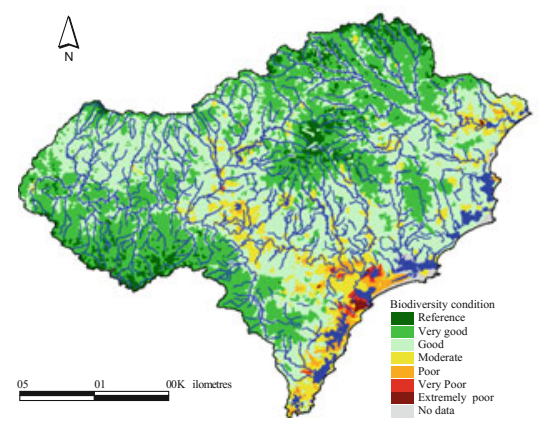

(b)

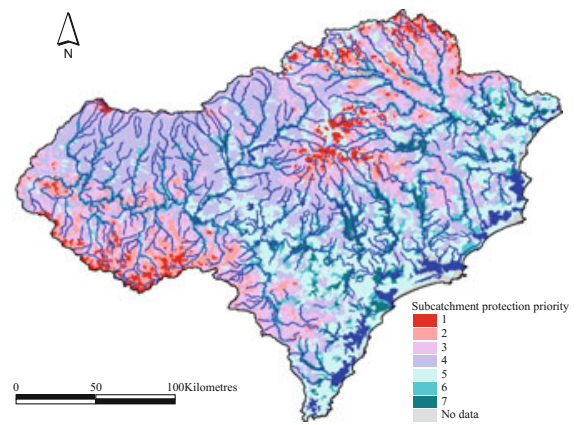

Fig. 7.3 Maps showing a patterns in river condition and $\mathbf{b}$ spatial priorities management actions aimed at protecting biodiversity, for the Hunter Catchment Management Region in south-eastern Australia (Source Turak et al. 2011)

on freshwater species or assemblages, as well as measures of environmental features that are intended to serve collectively as surrogates for all freshwater biodiversity. The success of actions at the drainage-basin scale is generally assessed through monitoring programs that use taxonomic composition of assemblages together with population trends of individual species.

\section{Box 7.3. Multiple use of freshwater biodiversity monitoring data to support freshwater conservation}

Biological monitoring programs in South-Eastern Australia have yielded extensive data on the composition of river macroinvertebrate and fish communities. These data were used in a variety of ways to support freshwater conservation in the region.

For example, occurrence records of macroinvertebrate families were used to develop predictive models that allowed quantitative scoring of river health at any given river site. These scores were then extrapolated using disturbance variables as predictors to generate digital layers of river condition (see Fig. 7.3a).

Another application of the data collected was in bottom-up biological classifications of rivers based on fish species records and macroinvertebrate family occurrences from relatively undisturbed reference sites. Digital layers representing these river classes together with the digital condition layers were used to generate maps representing spatial priorities for actions aimed at protecting river biodiversity (see Fig. 7.3b). 


\subsection{Future Directions for Freshwater Biodiversity Observations}

Improved access to freshwater biodiversity data, refinement of frameworks for regional, national and continental monitoring programs, the widespread application of freshwater conservation planning tools and methods, and advances in remote-sensing technology have allowed the development of new programmes to enhance the freshwater components of national, regional and global biodiversity observation networks. Some notable examples are given below.

\subsubsection{A Global Wetlands Observing System (GWOS)}

In 2008 the Scientific and Technical Review Panel of the Ramsar Convention on Wetlands initiated establishment of a Global Wetlands Observing System (GWOS) to bring together available information on the status and values of wetlands and water in a way that can support policy processes and decision making at various geographic scales. It will describe extent and condition as well as change and trends over time of a variety of wetland types.

Although GWOS is still in a development phase, several thematic and regional pilot projects have been implemented already or are ongoing. As an example of a thematic project, the Japanese Aerospace Exploration Agency's Global Mangrove Watch (http://www.eorc.jaxa.jp/ALOS/en/kyoto/mangrovewatch.htm) aims to contribute to GWOS and support the Ramsar Convention. Examples of regional pilots have been the European Space Agency-sponsored GlobWetland and GlobWetland II projects that demonstrated the value of earth observation in mapping and monitoring of wetlands. The current GlobWetland Africa project will demonstrate this on a continental scale for Africa. The Mediterranean Wetlands Observatory (http://www.medwetlands-obs.org) serves as another regional pilot project and the Global Freshwater Biodiversity Atlas demonstrates some of the capabilities GWOS is expected to have when it is established as a global system.

As the first broad implementation of GWOS, the EU Horizon 2020-sponsored project 'Satellite-based Wetlands Observation Service' (http://swos-service.eu/) that started in 2015 will develop a monitoring and information service for wetlands tailored to specific policy needs on different levels. The project will bring together satellite observation data and validation datasets and will use citizen science to produce maps and metrics on wetlands and make available both these outputs as well as the toolkit required to produce them.

In the end GWOS will rely on NGOs, inter-governmental organisations, biodiversity observation networks, research institutions and government agencies for data, analyses and the development of tools. Biodiversity observation networks can contribute to GWOS as suppliers of freshwater biodiversity data. GWOS, in turn, 
can improve the utility of freshwater biodiversity observations by bringing together policy-relevant information and knowledge to support actions aimed at protecting freshwater biodiversity.

\subsubsection{Citizen Science in Freshwater Biodiversity Observations}

Recent advances in communication technology and the associated proliferation of citizen science protocols, web-services and phone apps, has opened up new opportunities for volunteers to collect and upload large volumes of biodiversity data, especially digital photographs (see Chap. 9). So far these methods have been or are being successfully applied to freshwater vertebrates only but there is potential to include other macroscopic taxa. Citizen scientists have been significant contributors to waterbird observations for over 50 years, with International Waterbird Census volunteers numbering over 10,000 and covering more than a hundred countries. Quality control is essential in citizen science and new technologies allow better quality control of these observations. The Global Amphibian BioBlitz (http://www. amphibians.org/citizen-science/) has helped to increase recorded observations and create awareness about amphibian declines. The recently launched Freshwater Fish BioBlitz (http://www.iucnffsg.org/ffsg-activities-2/global-freshwater-fish-bioblitz/) offers the possibility of capturing a vast number of observations made by recreational fishermen, aquarists and other fish enthusiasts.

Citizen science has the potential to make significant contributions to our knowledge about species distributions and their monitoring. Despite huge advances, problems with the geographic bias of observations towards developed countries remain. Improved public engagement in many countries of the world will be essential for the success of citizen science initiatives, starting with diversifying the language used for communications, as many people that could contribute observations do not speak English, which is the primary language used by these networks.

\subsection{Conclusions}

Recent developments in freshwater biodiversity observations indicate that there is potential for evaluating the condition of freshwater biodiversity by 2020 in 'real-time' or close to it. Despite the incompleteness of national and continental assessments, it now seems possible that we have sufficient tools for making periodic evaluations of freshwater biodiversity across large regions a realistic possibility by 2020. This alone will not ensure protection of freshwater biodiversity but it will provide evidence for the effectiveness of current management actions in conserving 
freshwater biodiversity. This evidence is essential for getting better results with existing resources and justifying claims for additional resources.

Open Access This chapter is distributed under the terms of the Creative Commons AttributionNoncommercial 2.5 License (http://creativecommons.org/licenses/by-nc/2.5/) which permits any noncommercial use, distribution, and reproduction in any medium, provided the original author(s) and source are credited.

The images or other third party material in this chapter are included in the work's Creative Commons license, unless indicated otherwise in the credit line; if such material is not included in the work's Creative Commons license and the respective action is not permitted by statutory regulation, users will need to obtain permission from the license holder to duplicate, adapt or reproduce the material.

\section{References}

Abell, R., Thieme, M. L., Revenga, C., Bryer, M., Kottelat, M., Bogutskaya, N., et al. (2008). Freshwater ecoregions of the world: A new map of biogeographic units for freshwater biodiversity conservation. BioScience, 58, 403-414.

Ardura, A., Planes, S., \& Garcia-Vazquez, E. (2011). Beyond biodiversity: Fish metagenomes. PLOS ONE, 6, e22592.

Balian, E. V., Lévêque, C., Segers, H., \& Martens, K. (2008a). An introduction to the freshwater animal diversity assessment (FADA) project. Hydrobiologia, 595, 3-8.

Balian, E. V., Segers, H., Lévéque, C., \& Martens, K. (2008b). The freshwater animal diversity assessment: An overview of the results. Hydrobiologia, 595, 627-637.

Bush, A. A., Nipperess, D. A., Duursma, D. E., Theischinger, G., Turak, E., \& Hughes, L. (2014a). Continental-scale assessment of risk to the Australian Odonata from climate change. PLOS ONE, 9, e88958.

Bush, A. A., Nipperess, D. A., Theischinger, G., Turak, E., \& Hughes, L. (2014b). Testing for taxonomic bias in the future diversity of Australian Odonata. Diversity and Distributions, 20, 1016-1028.

Butchart, S. H. M., Walpole, M., Collen, B., van Strien, A., Scharlemann, J. P. W., Almond, R. E. E., et al. (2010). Global biodiversity: Indicators of recent declines. Science, 328, 1164-1168.

Carbonneau, P. E., \& Piégay, H. (Eds.). (2012). Fluvial remote sensing for science and management. Chichester, UK: Wiley.

Carrizo, S. F., Smith, K. G., \& Darwall, W. R. T. (2013). Progress towards a global assessment of the status of freshwater fishes (Pisces) for the IUCN Red List: Application to conservation programmes in zoos and aquariums. International Zoo Yearbook, 47, 46-64.

Collen, B., Whitton, F., Dyer, E. E., Baillie, J. E. M., Cumberlidge, N., Darwall, W. R. T., et al. (2014). Global patterns of freshwater species diversity, threat and endemism. Global Ecology and Biogeography, 23, 40-51.

CSIR. (2007). The South African River Health Programme. CSIR Natural Resources and the Environment. http://www.csir.co.za/nre/water_resources/pdfs/factsheet_rhp.pdf. Accessed March 17, 2016.

Culp, J. M., Goedkoop, W., Lento, J., Christoffersen, K. S., Frenzel, S., Guðbergsson, G., et al. (2012a): The Arctic Freshwater Biodiversity Monitoring Plan. CAFF International Secretariat, CAFF Monitoring Series Report Nr. 7. CAFF International Secretariat. Akureyri, Iceland. http://www.caff.is/publications/doc_download/196-arctic-freshwater-biodiversity-monitoringplan. Accessed March 17, 2016. 
Culp, J. M., Lento, J., Goedkoop, W., Power, M., Rautio, M., Christoffersen, K. S., et al. (2012b). Developing a circumpolar monitoring framework for Arctic freshwater biodiversity. Biodiversity, 13, 215-227.

Darwall, W. R. T., Smith, K. G., Allen, D. J., Holland, R. A., Harrison, I. J., \& Brooks, E. G. E. (Eds.). (2011). The diversity of life in African freshwaters: Under water, under threat. An analysis of the status and distribution of freshwater species throughout mainland Africa. Cambridge, United Kingdom and Gland, Switzerland: IUCN.

Davies, P. E., Harris, J. H., Hillman, T. J., \& Walker, K. F. (2010). The sustainable rivers audit: assessing river ecosystem health in the Murray-Darling Basin. Australian Journal of Marine and Freshwater Research, 61, 764-777.

De Wever, A., Schmidt-Kloiber, A., Gessner, M. O., \& Tockner, K. (2012). Freshwater journals unite to boost primary biodiversity data publication. BioScience, 62, 529-530.

Dudgeon, D. (2010). Prospects for sustaining freshwater biodiversity in the 21st century: Linking ecosystem structure and function. Current Opinion in Environmental Sustainability, 2, 422430.

Eschmeyer, W. N. \& Fong, J. D. (2015). Species by family/subfamily in the catalog of fishes. (http://researcharchive.calacademy.org/research/ichthyology/catalog/SpeciesByFamily.asp). Accessed December 24, 2015.

Ferrier, S. (2011). Extracting more value from biodiversity change observations through integrated modelling. BioScience, 61, 96-97.

Freyhof, J., \& Brooks, E. G. E. (2011). European red list of freshwater fishes. Publications Office of the European Union, Luxembourg, Luxembourg, 61 pp. http://ec.europa.eu/environment/ nature/conservation/species/redlist/downloads/European_freshwater_fishes.pdf. Accessed March 17, 2016.

Friberg, N., Bonada, N., Bradley, D. C., Dunbar, M. J., Edwards, F. K., Grey, J., et al. (2011). Biomonitoring of human impacts in freshwater ecosystems: The good, the bad, and the ugly. Advances in Ecological Research, 44, 2-68.

GEO BON. (2011). Adequacy of biodiversity observation systems to support the 2020 CBD targets. Group on Earth Observations Biodiversity Observation Network Office, Pretoria. http://www.earthobservations.org/documents/cop/bi_geobon/2011_cbd_adequacy_report.pdf. Accessed March 17, 2016.

Goldberg, C. S., Strickler, K. M., \& Pilliod, D. S. (2015). Moving environmental DNA methods from concept to practice for monitoring aquatic macroorganisms. Biological Conservation, 183, 1-3.

Hatton-Ellis, T. (2008). The hitchhiker's guide to the Water Framework Directive. Aquatic Conservation: Marine and Freshwater Ecosystems, 18, 111-116.

Hawkins, C. P. (2006). Quantifying biological integrity by taxonomic completeness: Evaluation of a potential indicator for use in regional and global-scale assessments. Ecological Applications, 16, 1277-1294.

Hebert, P., Cywinska, A., Ball, S., \& deWaard, J. (2003). Biological identification through DNA barcodes. Philosophical Transactions of the Royal Society B: Biological Sciences, 270, 313321.

Heiner, M., Higgins, J., Li, X. H., \& Baker, B. (2011). Identifying freshwater conservation priorities in the Upper Yangtze River Basin. Freshwater Biology, 56, 89-105.

Iversen, L. L., Kielgast, J., \& Sand-Jensen, K. (2015). Monitoring of animal abundance by environmental DNA-An increasingly obscure perspective: A reply to Klymus et al. 2015. Biological Conservation, 192, 479-480.

Lehner, B., Verdin, K., \& Jarvis, A. (2008). New global hydrography derived from spaceborne elevation data. EOS. Transactions of the American Geophysical Union, 89, 93-94.

Lehner, B., \& Grill, G. (2013). Global river hydrography and network routing: baseline data and new approaches to study the world's large river systems. Hydrolic Process, 27, 2171-2186.

Linke, S., Turak E., \& Nel, J. (2011). Freshwater conservation planning: the case for systematic approaches. Freshwater Biology, 56, 6-20. 
McLellan, R., Iyengar, L., Jeffries, B., \& Oerlemans, N. (2014). Living planet report 2014: species and spaces, people and places. Gland, Switzerland: WWF International.

Pereira, H. M., Ferrier, S., Walters, M., Geller, G. N., Jongman, R. H. G., Scholes, R. J., et al. (2013). Essential Biodiversity Variables. Science, 339, 277-278.

Poff, N. L., Brown, C. M., Grantham, T. E., Matthews, J. H., Palmer, M. A., Spence, C. M., et al. (2015). Sustainable water management under future uncertainty with eco-engineering decision scaling. Nature Climate Change. Published online September 14, 2015.

Reid, G Mc G, Contreras MacBeath, T., \& Csatádi, K. (2013). Global challenges in freshwater-fish conservation related to public aquariums and the aquarium industry. International Zoo Yearbook, 47, 6-45.

Revenga, C., Campbell, I., Abell, R., De Villiers, P., \& Bryer, M. (2005). Prospects for monitoring freshwater ecosystems towards the 2010 targets. Philosophical Transactions of the Royal Society B: Biological Sciences, 360, 397-413.

Schmidt-Kloiber, A., \& Hering, D. (2015). www.freshwaterecology.info-An online tool that unifies, standardises and codifies more than 20,000 European freshwater organisms and their ecological preferences. Ecological Indicators, 53, 271-282.

Silk, N., \& Ciruna, K. (Eds.). (2005). A practitioner's guide to freshwater biodiversity conservation. The Nature Conservancy. Washington, USA: Island Press.

Strayer, D. L., \& Dudgeon, D. (2010). Freshwater biodiversity conservation: Recent progress and future challenges. Journal of the North American Benthological Society, 29, 344-358.

Taberlet, P., Coissac, E., Hajibabaei, M., \& Rieseberg, L. H. (2012). Environmental DNA. Molecular Ecology, 21, 1789-1793.

Thomsen, P., Kielgast, J. O. S., Iversen, L. L., Wiuf, C., Rasmussen, M., Gilbert, M. T. P., et al. (2012). Monitoring endangered freshwater biodiversity using environmental DNA. Molecular Ecology, 21, 2565-2573.

Turak, E., Ferrier, S., Barrett, T. O. M., Mesley, E., Drielsma, M., Manion, G., et al. (2011). Planning for the persistence of river biodiversity: Exploring alternative futures using process-based models. Freshwater Biology, 56, 39-56.

Turak, E., Harrison, I. J., Dudgeon, D., Abell, R., Bush, A., Darwall, D., et al. (2016). Essential Biodiversity Variables for measuring change in global freshwater biodiversity. Biological Conservation. http://dx.doi.org/10.1016/j.biocon.2016.09.005

USEPA. (2013). National rivers and streams assessment 2008-2009: a collaborative survey. EPA/841/D-13/001. Office of wetlands, oceans and watersheds and office of research and development, Washington, DC. http://nepis.epa.gov/Exe/ZyPURL.cgi?Dockey=P100AVOF. TXT

Vörösmarty, C. J., McIntyre, P. B., Gessner, M. O., Dudgeon, D., Prusevich, A., Green, P., et al. (2010). Global threats to human water security and river biodiversity. Nature, 467, 555-561. 